chemical examination of waters have been made, as well as investigations on bacteria in sea water and their rôle as denitrifiers. A two-hourly meteorological record was maintained, and the pilot balloon work was very successful. An interesting fact established is that the violent winds of certain parts of the Antaretic are mainly confined to the surface, seldom extending more than $500 \mathrm{ft}$. or $1000 \mathrm{ft}$. above groundlevel. Useful observations in magneties, solar radiation, and cosmic penetration have been made, while, of course, a rich harvest has been reaped in glaciology, geology, and ornithology.

The Discovery sailed from Melbourne about the middle of April and, if not delayed, may be expected in London shortly.

\section{A New Heat Engine.}

$A^{\mathrm{T}}$ the Royal Society of Arts on June 4, Mr. J. F. J. Malone, in a paper entitled "A New Prime Mover ", gave a description of a form of heat engine, invented by himself, in which the working medium is a liquid instead of a gas. In the course of his paper he stated that though mercury and oil have been tried, water has been found to be the most suitable medium, and in the engines to which reference was made only water has been used.

The main parts of the new form of engine consist of one or more working cylinders, a large number of long thick steel tubes in each of which is a movable displacer or regenerator, and a furnace. The tubes the author calls the thermodynamic tubes or 'T.D. tubes', and the regenerators, the thermodynamic piles or 'T.D. piles'. The tubes are closed at one end and at the other end are connected by pipes to the working cylinders. They are set in groups with their closed ends in the furnace, while the other ends are surrounded by water for cooling. The T.D. piles are built up of thin plates or tubes very closely spaced. The interior of the T.D. tubes, the very narrow spaces in the piles, the connecting pipes, and the working cylinders form a closed system completely full of water, which, when the engine is prepared ready for starting, is under an initial pressure of 1.4 tons per sq. in.

The engine depends for its action on the alternate expansion and contraction of the water in the system, due to the heating and cooling of the water in the T.D. tubes and piles, as the latter are moved to and fro in the tubes. For all practical purposes, the moving of the piles, which is done automatically by the engine, is equivalent to the alternate application and removal of the source of heat. Under these conditions the moving of the piles causes the pressure to rise to about 5.3 tons in one part of the stroke and then to fall to 1.4 tons per sq. in. Much ingenuity has been shown in the construction of the piles, which at first sight might appear likely to give trouble, but which have proved reliable on service.

Unfortunately, though the paper gave a few details of the several engines which have been built and run, these were by no means sufficient to form an estimate of the place the engine is likely to fill. One experimental engine was said to have run over $30,000,000$ revolutions, and on three brake tests by three different independent engineers an indicated efficiency of 27 per cent was obtained. It was also stated that allowing for furnace and mechanical losses, it was anticipated with a 100 h.p. engine an over-all efficiency of 20 per cent can be obtained, and this on a weight of about $330 \mathrm{lb}$. per indicated horse power. In the conclusion of his paper Mr. Malone claimed that the new engine possesses features which make it suitable both for locomotives and for ships.

\section{University and Educational Intelligence.}

Birmingham.--The degree of D.Sc. has been awarded to the following: Jonquei Su-Kwang Lee, for published work on "The Fusulinidæ of North China " (Palceontologia Sinica, series B, vol. 4), "Some Characteristic Structural Types in Eastern Asia and their Bearing upon the Problem of Continental Movement", "Geology of the Gorge District of the Yang-tse with special Reference to the Development of the Gorge ", and other papers ; Harry W. Webb. for published work on "Absorption of Nitrous Gases ", "Limitation of the Capacity of Platinum Catalyst" in Ammonia Oxidation ", and other papers.

Dr. A. Stanley Barnes has been appointed Dean of the Faculty of Medicine, in succession to Prof. Brash.

The following appointments have been made: Dr. R. H. Hoplsins, lecturer and head of the Department of Brewing in the Heriot-Watt College, Edinburgh, to the Adrian Brown chair of brewing; Mr. R. D. Lockhart, lecturer in anatomy, University of Aberdeen, to the chair of anatomy; Mr. P. Gray and Mr. D. Richards, to be resident staff tutor's for adult education under the Joint Committee of the Tniversity and the W.E.A.

Prof. A. M. Carr-Saunders has accepted an invitation to hold the Muirhead Lectureship for a further year.

CAMrridge.-The Harkness scholarship for proficiency in geology, of value $£ 117$, has been awarded to Miss F. E. S. Caldwell, of Newnham College.

The Frank Smart prizes have been awarded to P. W. Richards, of Trinity College, for botany, and P. Ullyett, of 'Trinity College, for zoology.

EDINBURGH. - At the graduation ceremony on July 2 the honorary degree of doctor of laws was conferred on the following, among others: Dr. E. J. Allen, Director of the Marine Biological Laboratory, Plymouth ; Sir George Andreas Berry, M.P. for the Scottish Universities, formerly lecturer in ophthalmo logy in the University of Edinburgh; and Sir Walter Morley Fletcher, secretary of the Medical Research Council.

The degree of doctor of science was conferred on Lucy Boyd, for a thesis on "Studies in the PostSeminal Development of the Monocotyledonous Embryo "; A. Cunningham, for a thesis on "Studies on Soil Micro-Organisms"; Esmé Mary Gilroy, for a thesis on "The Influence of Arginine upon Growth and Tissue Repair" ; Dr. M. Young, for a thesis on "A Contribution to the Study of the Growth of the Face in Childhood".

LEEDS.-At a graduation ceremony in connexion with the hundredth anniversary of the Leeds School of Medicine, the following honorary degrees were conferred, among others: Degree of doctor of lawsProf. A. G. Barrs, emeritus professor of medicine at Leeds and for more than fifty years connected with the School of Medicine; Sir John Bland-Sutton, consulting surgeon at the Middlesex Hospital ; Lord Dawson of Penn, president of the Royal College of Physicians; and Sir George Newman, Chief Medical Officer, Ministry of Health. Degree of doctor of science-Sir Walter Morley Fletcher, secretary of the Medical Research Council ; and Sir Frederiek Gowland Hopkins, president of the Royal Society

London.--The late Mr. J. F. H. Knight has bequeathed to the University a moiety of his residuary estate for the furtherance of teaching and research in the University. The bequest is expected to amount to about $£ 25,000$. 
NotringhaM.-Dr. Henry L. Brose, at present reader in atomic physics, formerly Rhodes Scholar at Christ Church, Oxford, has been appointed to the chair of physics, which is about to become vacant owing to the retirement of Prof. P. E. Shaw.

ST. ANDREws.-At a meeting of the University Court on June 23, Dr. F. L. Arnot, of Trinity College, Cambridge, was appointed lecturer in natural philosophy in the United College, St. Andrews, as from Oct. 1. Dr. George L. Montgomery was appointed lecturer in clinical pathology in the University.

The Court confirmed the acceptance of contracts for the erection of a new building for the botany and geology departments, a new lecture theatre for the zoology department, and a new laboratory for the anatomy department, to form part of the group of Bute Medical and Bell-Pettigrew Museum Buildings at St. Andrews.

DR. J. D. STuRLING has recently been appointed to the staff of the Hannah Dairy Research Institute, Kirkhill, Auchineruive, Ayr. For the past three years Dr. Stirling has been doing research work in biochemistry at the University of Glasgow under the direction of Prof. E. P. Cathcart, and later at Tübingen in Germany and Graz in Austria.

Tre second year's awards of the Sir James Caird Travelling Scholarships have recently been announced. The scholarships were instituted by the will of the late Mrs. Emma Grace Marryat, who was a sister of the late Sir James Caird, Bart., of Dundee. A sum of $£ 200,000$ was appointed to be held in trust for the foundation of the scholarships in engineering, electricity, aeronautics, and music. Only natives of Scotland, of either sex, who are not already holders of scholarships similar in nature to those offered, are eligible for these scholarships. Two classes, junior and senior, are offered. The value of the junior varies from $£ 50$ to $£ 150$ and the senior from $£ 250$ to $£ 600$ per annum. Each scholarship is tenable for one year but may be extended yearly to a maximum of three years. Among the scholarships awarded for this year were the following: Engineering (junior of the maximum of $£ 150$ ), T. C. Inglis, W. A. Sangster; (senior of the normal amount of $£ 400$ ), J. Jamieson. Electricity (junior of the maximum of $£ 150$ ), J. C. M. Sanders, H. C. Thompson; (senior of the normal amount of $£ 400$ ), M. D. Kippen, J. M. Dodds. Aeronqutics (senior scholarship of $£ 300$ ), J. A. $J$. Bennet.

Tre Medical Research Council has made the ollowing awards of travelling Fellowships for the academic year 1931-32 on behalf of the Rockefeller Foundation : Mr. E. T. Conybeare, Guy's Hospital, London; Mr. G. M. Dean, Department of Surgery, University of Aberdeen; Mr. M. H. Finkelstein, Department of Bacteriology, University of Edinburgh; Prof. O. S. Gibbs, formerly professor of pharmacology, Dalhousie University, Canada; Mr. E. M. Lourie, Liverpool School of Tropical Medicine; Mr. A. W. Spence, St. Bartholomew's Hospital, London; Mr. C. H. Waddington, Strangeways Research Laboratory Cambridge; M. K. H. Watkins, Royal Infirmary, Manchester. The Fellowships awarded to Prof. Gibbs and Mr. Waddington are tenable in Europe, the others at centres in the United States. These Fellow. ships are awarded to graduates who have had some training in research work either in the primary sciences of medicine or in clinical medicine or surgery, and are likely to profit by a period of work at a chosen centre in the United States or, in special cases, in Europe, before taking up positions for higher teaching or research in the British Isles.

\section{Societies and Academies.}

\author{
EDINBurgh.
}

Royal Society, June 15.-A. H. Reginald Buller : (An address) Recent advances in our knowledge of the higher fungi. A mushroom is the reproductive part of the mushroom plant and is produced at the expense of the mycelium or spawn. A large mushroom may develop and liberate upwards of $10,000,000,000$ spores. The basidiospores of all Hymenomycetes, all Uredineæ, the smut-genus Tilletia, and the yeast-genus Sporobolomyces are shot away by a drop-excretion mechanism, but exactly how this mechanism works is still a profound mystery. The terminal rate of fall of spores in still air varies with the size of the spores from about 0.5 to $4.0 \mathrm{~mm}$. per sec. Spores are discharged from the under side of the caps of mushrooms and toadstools in a continuous stream for days or weeks. The clouds of spores escaping from a fruitbody can be made visible in a darkened room by means of a beam of light. Nocturnal excursions with an electric lamp may be made to observe sporedischarge from fruit-bodies attached to tree-trunks, etc. The organisation of the hymenium which covers the gills of mushrooms and toadstools has been worked out, and the time and space relations of the basidia which produce the spores and of the sterile elements called paraphyses are now known. The basidia come to maturity in a series of successive generations. The sexual process in mushrooms and toadstools is initiated in the mycelium with nuclear association, is continued there with conjugate nuclear divisions, and is completed in the fruit-body by nuclear fusion in every basidium.-J. Thomson: The ionising efficiency of electronic impacts in air : Experiments are described, the aim of which is the determination of the average energy required to produce one pair of ions in air by electronic impact, the initial energy of the electron being defined. The results show that the total number of ions produced is a linear function of the initial electronic energy. Hence it is shown by extrapolation that for fast-moving electrons (such as $\beta$-rays) the energy per ion-pair is $37 \pm 2$ electron-volts. This result is discussed in relation to other investigations, and the extrapolation is thereby justified.

\section{Paris.}

Academy of Sciences, May 18.-A. Lacroix: The nepheline and leucite phonolites of the island of Ua-Pou (Marquesas Archipelago).-A. Cotton : Comparison of the magnetic rotations of crystallised quartz and fused quartz. The specific magnetic rotation of fused quartz was found to be greater than that of crystallised quartz. - L. Cayeux: The petrographie characters of the magnesian irregularities in the chalk of the Paris basin.-Charles Richet: The reflexes of acquisition (Pavloff's conditional reflexes). A claim for priority as regards the work of Pavloff.--Charles Nicolle and Ugo Lumbroso: The Bacterium granulosa of Noguchi in its relations with the etiology of trachoma. Two strains of this bacillus (Noguchi, Olitski) proved to be devoid of pathogenic power. It is mentioned as possible that there might have been an attenuation of the virulence due to the age of the culture.-S. Finikoff : Congruences of which the two sheets of the focal surface are projectively applicable one on the other by the corresponding focal points. Marcel Vasseur: A geometrical interpretation of Moutard's transformation.--I. Leray: A system of partial differential equations which governs the permanent flow of viscous fluids.-Mile. Nina Bary: The representation of continued functions by means of functions with limited variation.--R. Gosse: The investigation of a category of equations of the first.

No. 3219, Vox. 128] 